\title{
Pool boiling visualization of Novec-649 and FC-72 on copper microchannels
}

\author{
Robert Kaniowski ${ }^{1, *}$, and Robert Pastuszko ${ }^{1}$ \\ ${ }^{1}$ Kielce University of Technology, Faculty of Mechatronics and Mechanical Engineering, al. 1000-lecia Państwa Polskiego 7, \\ PL-25-314 Kielce, Poland
}

\begin{abstract}
Saturated pool boiling from copper microchannel surfaces was examined using Novec-649 and FC-72 as working fluids. Parallel microchannels fabricated by machining were about $0.2 \mathrm{~mm}$ wide, and 0.2 to $0.4 \mathrm{~mm}$ deep and spaced every $0.4 \mathrm{~mm}$. The experiments were carried out at atmospheric pressure. The images of the growing and departing bubbles for the entire surface of the specimen were taken with a Photonfocus PHOT MV-D1024-160-CL camera and an EX-FH20 (Casio) camera. At low superheats, the bubbles departing from enhanced surfaces were spherical in shape and did not coalesce. At higher superheats, the bubbles interacted with each other intensively, forming flattened spherical, funnel-shaped bubbles at the bottom. The visualization study aimed at identifying nucleation sites of the departing bubbles and determining their diameters and frequency at various superheats.
\end{abstract}

\section{Introduction}

The growing demand for miniaturization entails seeking ever better cooling technologies that will prevent mechanical and electronic components from temperature overshoot. The highest heat flux at a small temperature difference between the heating surface and the working fluid and a small heat removal surface can be obtained through a phase change accompanying boiling and condensation processes. Pool boiling from specially prepared surfaces helps obtain an additional increase in the heat transfer coefficient, which, in relation to the heat exchanger, translates to higher values of the overall heat transfer coefficient.

Gouda et al. [1] conducted experimental studies to investigate the heat transfer characteristics of segmented finned microchannels structured surface and compare its performance with that of uniform cross-section microchannels structured surface and plane surface. The authors used deionized water in their experiments at atmospheric pressure. At low heat fluxes, nucleation started earlier and more nucleation sites were observed on the segmented finned structured surface compared to the uniform microchannel surface.

In [2], the authors presented effect of varying diameter of metal nanowires on pool boiling heat transfer performance. An increase in $\mathrm{CHF}$ for the specimens with nanowires was about $40 \%$ and about $100 \%$ in heat transfer coefficient as compared to the smooth surface. A dielectric fluid (FC-72) was used as the working fluid at atmospheric pressure.

Walunj and Sathyabhama [3] investigated rectangular, parabolic and stepped microchannels fabricated on the $10 \mathrm{~mm}$ diameter copper rod with channel widths: $250-800 \mu \mathrm{m}$, height of $500 \mu \mathrm{m}$. Water was used as the working fluid. At the heat flux of 100 $\mathrm{kW} / \mathrm{m}^{2}$, the HTC increased by $21-35 \%$.

Z. Cao et al. [4] fabricated two types of micro-pinfin configurations on silicon surfaces by a dry etching method, i.e., staggered pin fins and aligned pin fins with empty areas. Experiments were carried out at atmospheric pressure, using FC-72 as the working fluid. The results showed that in comparison to the smooth surface, pool boiling heat transfer was significantly enhanced by the micro-pin-fin surfaces and the maximum superheat was considerably decreased.

Jaikomar and Kandlikar [5] performed studies on the heat transfer on specimens of copper surface in form of open microchannels with porous fin tops at atmospheric pressure using FC-87 as boiling fluid. The highest HTC of $20 \mathrm{~kW} / \mathrm{m}^{2} \mathrm{~K}$ was obtained.

The purpose of this article was to determine the effect of microchannel fins on the HTC for the boiling fluid (Novec-649, FC-72) and to identify diameters and frequency of departing bubbles.

The Kielce University of Technology has been conducting studies on pool boiling heat transfer with water, ethanol, FC-72 and Novec-649 from tunnel structures, microfins, microchannels, microcavities [610] and boiling heat transfer with FC-72 flowing in narrow channels [11-15] for more than a decade.

\section{Experimental setup}

The experimental set-up was designed to measure the superheat of the heated surface $\Delta T$ for the set heat flux value and to record the process of bubble formation (Fig. 1 and Fig. 2). Temperature was measured using $K$ type thermocouples. FLUKE Hydra series II data acquisition system was applied. The image acquisition speed was

Corresponding author: kaniowski@tu.kielce.pl 
493 fps (from a Photonfocus PHOT MV-D1024-160-CL camera with a resolution of $400 \times 300$ ) and the images of the entire surface of the specimen were recorded using an EX-FH20 (Casio) camera. The heat transfer process in the microchannel was studied for nucleate pool boiling. The level of fluid above the specimen surface was more than $50 \mathrm{~mm}$. Prior to the measurements, the fluid was degassed through boiling at heat flux of about $50 \mathrm{~kW} / \mathrm{m}^{2}$. The boiling was retained for about 15 minutes. Six thermocouples were inserted along the length of the copper bar as shown in Fig. 3a to obtain accurate estimation of heat flux and surface temperature. Two thermocouples under the specimen (T3 and T4) were embedded to extrapolate its temperature to the level of microchannel bottoms. Four thermocouples $T 5$ to $T 8$ were mounted to measure the temperature gradient and distribution in the cylinder. Fig. 3 b) shows a view of the specimen with microchannels.

The square specimens $32 \times 32 \mathrm{~mm}^{2}$ were made of copper and had parallel grooves with a constant pitch, made with an end mill of $0.2-0.4 \mathrm{~mm}$ in diameter (CNC machining process). The test section had a $27 \times 27$ $\mathrm{mm}^{2}$ boiling region. The mean roughness of the microchannel surface was $0.15 \mu \mathrm{m}$.

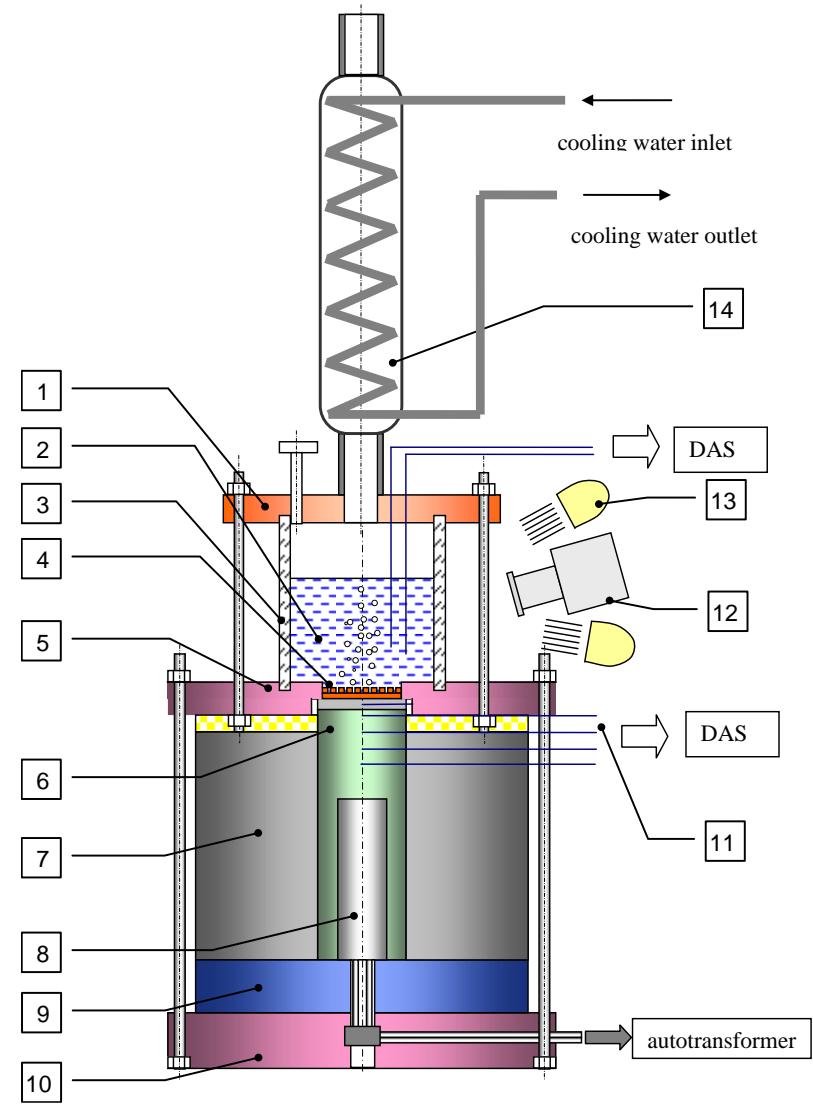

Fig. 1. Main module; 1 - top flange, 2 - boiling liquid, 3 glass vessel, 4 - specimen, 5 - Teflon annular flange, 6 copper bar, 7 - insulation, 8 - cartridge heater, 9 - bottom insulation, 10 - retaining flange, 11 - thermocouples, $12-$ digital camera, 13 - lights, 14 - condenser, DAS - Data Acquisition System.

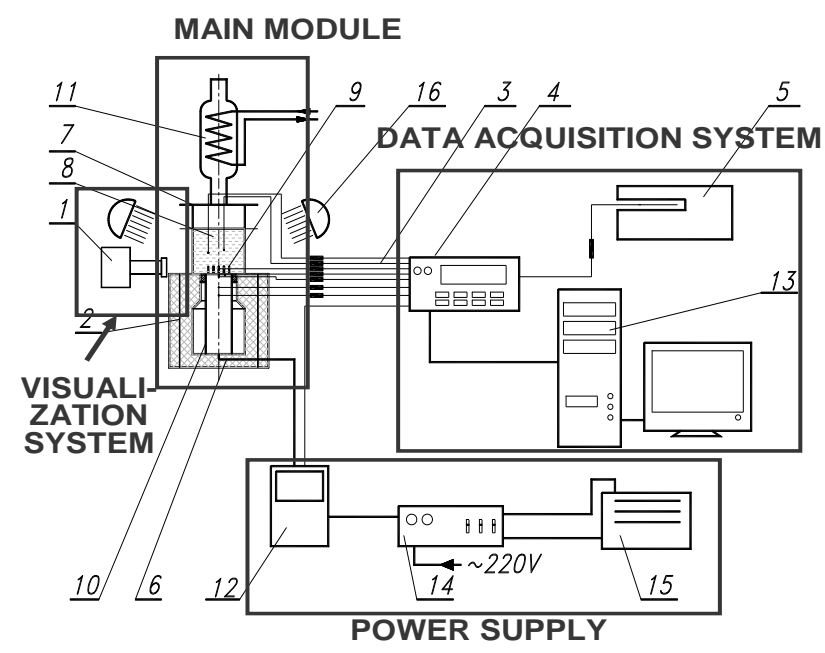

Fig. 2. Pool boiling measurement stand: 1 - digital camera, $2-$ Teflon casing, 3 - compensating leads, 4 - data logger, 5 - drywell calibrator, 6 - insulation, 7 - glass vessel, 8 - boiling liquid, 9 - investigated specimen, 10 - copper bar with cartridge heater, 11 - condenser, 12 - wattmeter, 13 - PC, $14-$ power supply and fuses, 15 - autotransformer, 16 - lights.

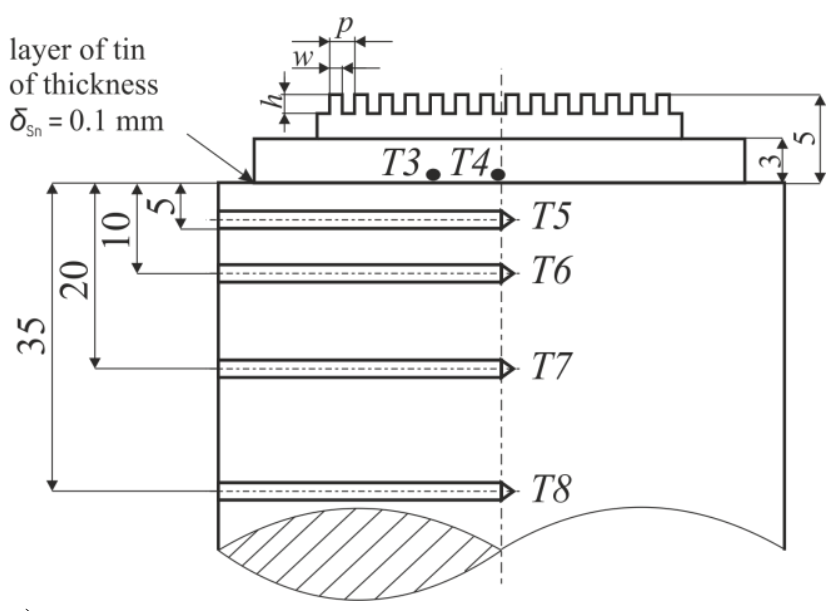

a)

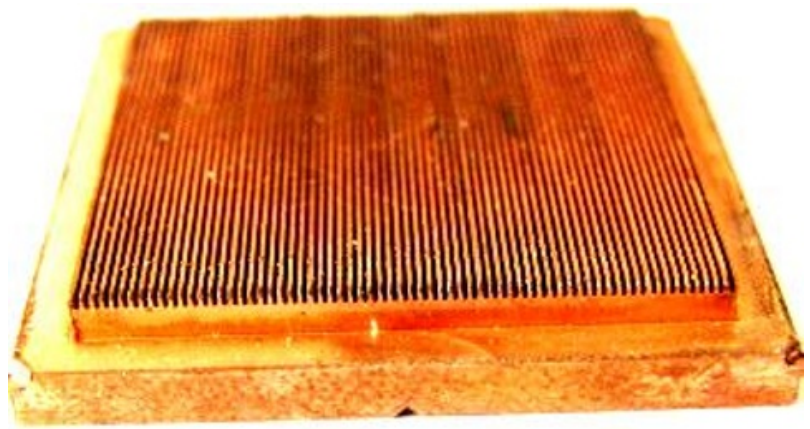

b)

Fig. 3. a) dimensions and symbols of $\mathrm{MC}$, and the arrangement of thermocouples, $b$ ) view of the MC specimen. 
With the assumption that the heat transfer is onedimensional, the heat flux was calculated on the basis of the temperature gradient in the upper part of the copper bar from:

$$
q=\frac{\lambda_{C u}\left(T_{T 8}-T_{T 5}\right)}{l_{T 5-T 8}},
$$

where: $l_{T 5-T 8}=30 \mathrm{~mm}$ is the distance between thermocouples $T 5$ and $T 8$.

In this study, $T_{w}$ was extrapolated by

$$
T_{w}=\frac{T_{T 3}+T_{T 4}}{2}-q\left(\frac{\delta_{s}}{\lambda_{C u}}+\frac{\delta_{S n}}{\lambda_{S n}}\right),
$$

where $\delta_{s}$ is the distance between microchannel bottom (base) and thermocouples T3 and T4.

The differences in the temperatures of the heated surface and liquid $\Delta T$ (superheat) is shown by the following equation:

$$
\Delta T=T_{w}-\frac{T_{T 1}+T_{T 2}}{2},
$$

By Newton's law of cooling, it can be written as:

$$
\alpha=\frac{q}{\Delta T}
$$

Table 1 compiles the surface codes and specifications according to Fig. $3 \mathrm{a}$.

Table 1. MC surface codes and specifications.

\begin{tabular}{lccc}
\hline Code & $\begin{array}{l}w \\
\mathrm{~mm}\end{array}$ & $\begin{array}{l}h \\
\mathrm{~mm}\end{array}$ & $\begin{array}{l}p \\
\mathrm{~mm}\end{array}$ \\
\hline MC-0.2-0.4-0.4 & 0.2 & 0.4 & 0.4 \\
MC-0.2-0.3-0.4 & 0.2 & 0.3 & 0.4 \\
MC-0.2-0.2-0.4 & 0.2 & 0.2 & 0.4 \\
\hline
\end{tabular}

The errors in superheat, heat flux and heat transfer coefficient determination were estimated taking $\pm 0.2 \mathrm{~K}$ as measurement uncertainty in the value of the independent parameter. The uncertainty of the distance between the thermocouples was determined as $4 \%$. The calculated measurement uncertainties were as follows:

- at low heat flux $\left(2 \mathrm{~kW} / \mathrm{m}^{2}\right)$ relative error of heat flux $\pm 35 \%$, relative error of heat transfer coefficient $\pm 40 \%$,

- at high heat flux $\left(130 \mathrm{~kW} / \mathrm{m}^{2}\right)$ relative error of heat flux $\pm 27 \%$, relative error of heat transfer coefficient $\pm 31 \%$.

\section{Results}

Two types of structures (plain surface and surface with microchannels) were examined to study the influence of enhanced surface on boiling heat transfer coefficient and compare their performance for two different fluids (Novec-649, FC-72). The experimental range of the supplied heat flux was from the natural convection to the CHF.

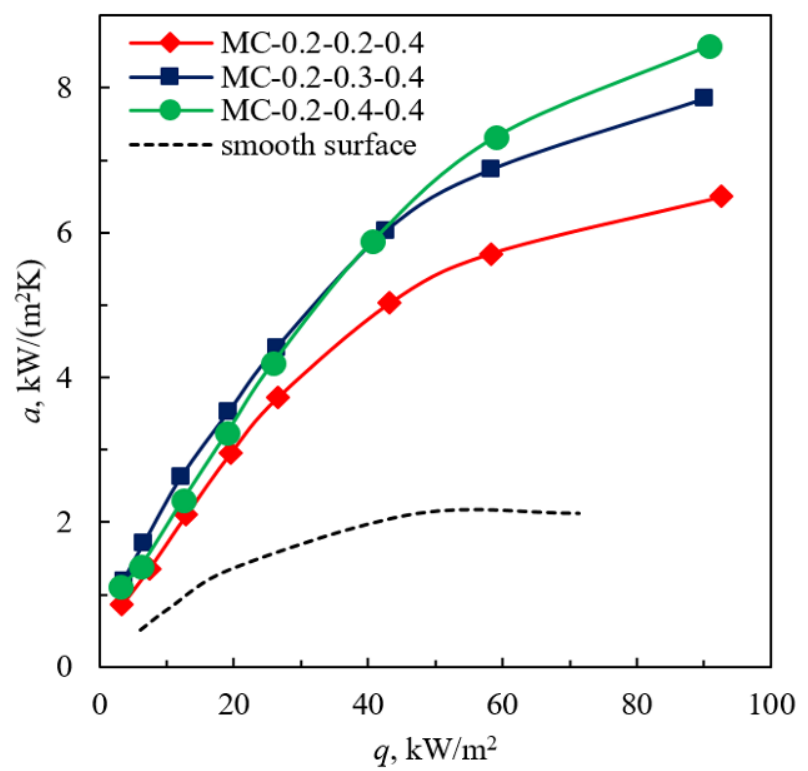

Fig. 4. Boiling curves for Novec-649, heat transfer coefficient vs. heat flux.

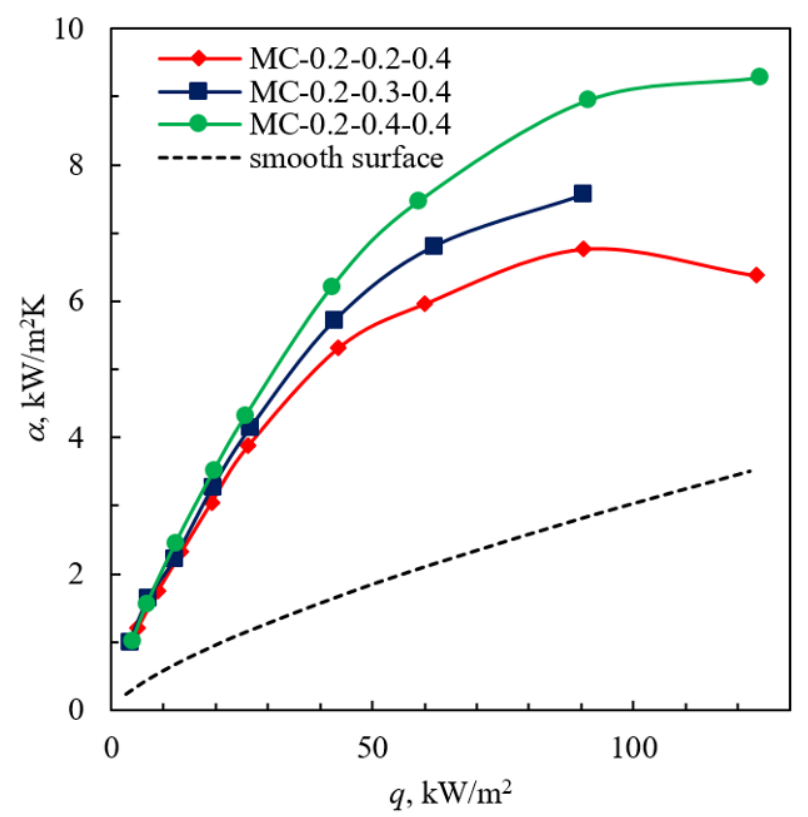

Fig. 5. Boiling curves for FC-72, heat transfer coefficient vs. heat flux.

The best results were recorded for MC-0.2-0.4-0.4, where the heat transfer coefficient was $8.6 \mathrm{~W} / \mathrm{m}^{2} \mathrm{~K}$ at a superheat of $10.6 \mathrm{~K}$ for Novec-649 and HTC was 9.3 $\mathrm{W} / \mathrm{m}^{2} \mathrm{~K}$ at a superheat of $13.4 \mathrm{~K}$ for FC-72 (Figs 4,5).

Observations of the boiling process carried out in the heat flux range of $3-43 \mathrm{~kW} / \mathrm{m}^{2}$ allowed identifying two boiling regimes (Figs 6,7):

1. Isolated bubble regime (Figs $6 \mathrm{a}, \mathrm{b}$ and $7 \mathrm{a}, \mathrm{b}$ ) $; 3.3-7.3$ $\mathrm{kW} / \mathrm{m}^{2}$ for Novec-649, $5-8.8 \mathrm{~kW} / \mathrm{m}^{2}$ for FC-72. Single bubbles tended to increase in diameter with increasing heat flux - a three-fold increase from about $0.5 \mathrm{~mm}$ to $1.5 \mathrm{~mm}$ for both working fluids (Fig.8), accompanied by a small increase in frequency (by about 20\%, Fig. 9) was recorded.

2. Partial coalescence regime (Figs 6c-f and 7c-f); 12.9 $-43.2 \mathrm{~kW} / \mathrm{m}^{2}$ for Novec-649, $13.4-43.5 \mathrm{~kW} / \mathrm{m}^{2}$ for FC-72. The number of active nucleation sites 
increased. Single large bubbles were seen closer to the edge of the specimen. Towards the centre, the bubbles merged intensely. For both fluids, diameters of the uncoalesced bubbles stabilized at about 1.5 $\mathrm{mm}$ (Fig. 8). In the heat flux range under analysis, the bubble departure frequency also showed minor changes and reached $100-110 \mathrm{~Hz}$. In the case of large irregular structures (cloud formation) formed from the merged bubbles, the frequencies were substantially lower, but heat amounts required for their growth and detachment were large enough to contribute to a significant increase in heat flux and HTC.
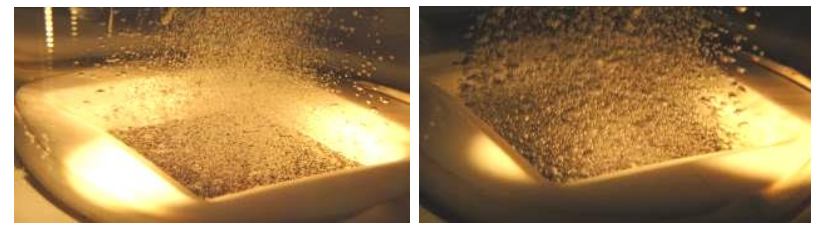

a)

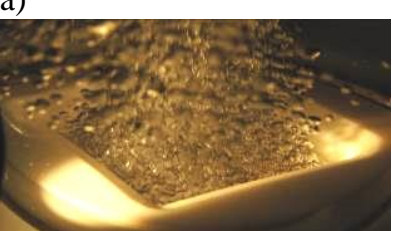

b)

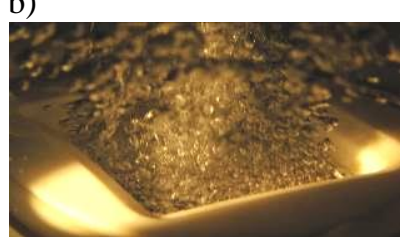

c) d)
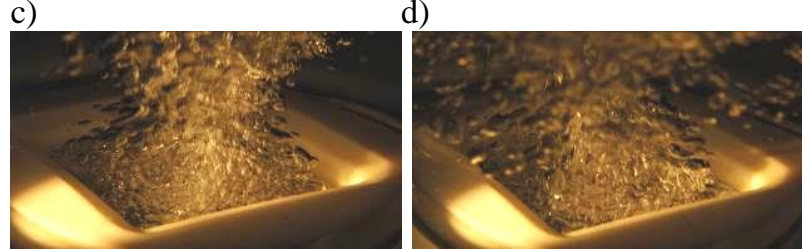

f)

e)

Fig. 6. Visualization of pool boiling with Novec-649 on the microchannel surface MC-0.2-0.2-0.4, a) $q=3.3 \mathrm{~W} / \mathrm{m}^{2}$, b) $q=$ $7.3 \mathrm{~kW} / \mathrm{m}^{2}$, c) $q=12.9 \mathrm{~kW} / \mathrm{m}^{2}$, d) $q=19.5 \mathrm{~kW} / \mathrm{m}^{2}$, e) $q=26.5$ $\left.\mathrm{kW} / \mathrm{m}^{2}, \mathrm{f}\right) q=43.2 \mathrm{~kW} / \mathrm{m}^{2}$.
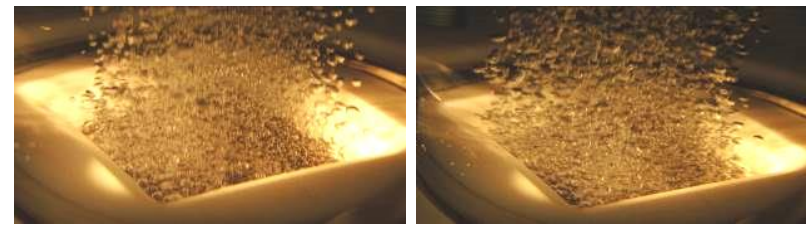

a)

b)

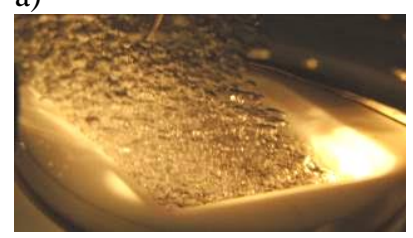

c)

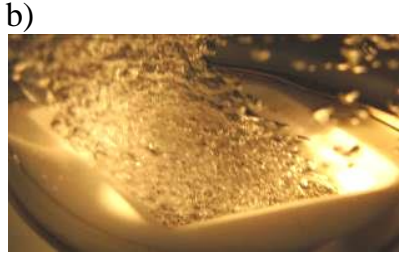
d)
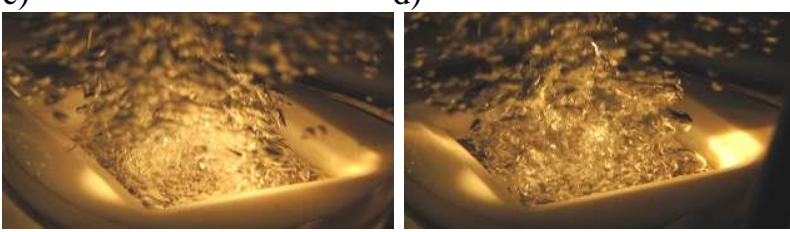

e)

f)

Fig. 7. Visualization observations of pool boiling of FC-72 on the microchannel surface MC-0.2-0.2-0.4, a) $q=5.0 \mathrm{~W} / \mathrm{m}^{2}$, b) $q=8.8 \mathrm{~kW} / \mathrm{m}^{2}$, c) $q=13.4 \mathrm{~kW} / \mathrm{m}^{2}$, d) $q=19.1 \mathrm{~kW} / \mathrm{m}^{2}$, e) $q=$ $26.2 \mathrm{~kW} / \mathrm{m}^{2}$, f) $q=43.5 \mathrm{~kW} / \mathrm{m}^{2}$.

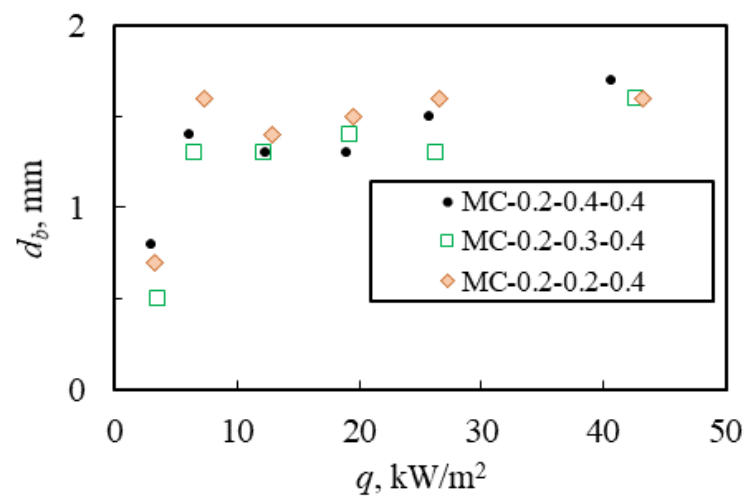

a)

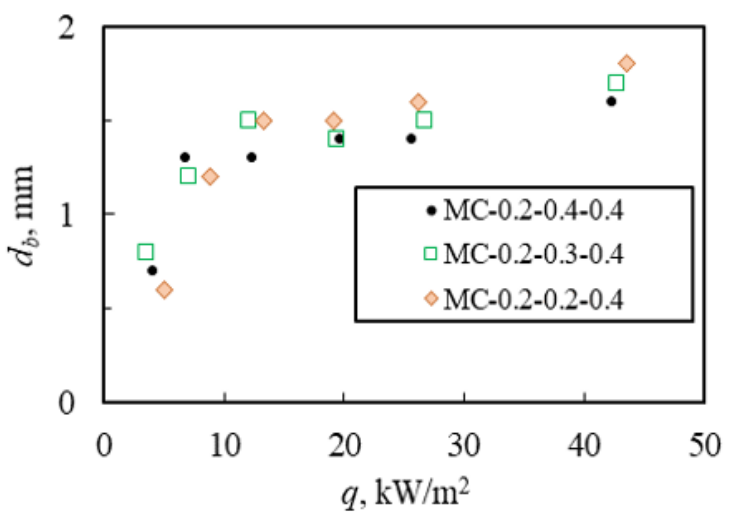

b)

Fig. 8. Averaged bubble departure diameters with a) Novec649 , b) FC-72.

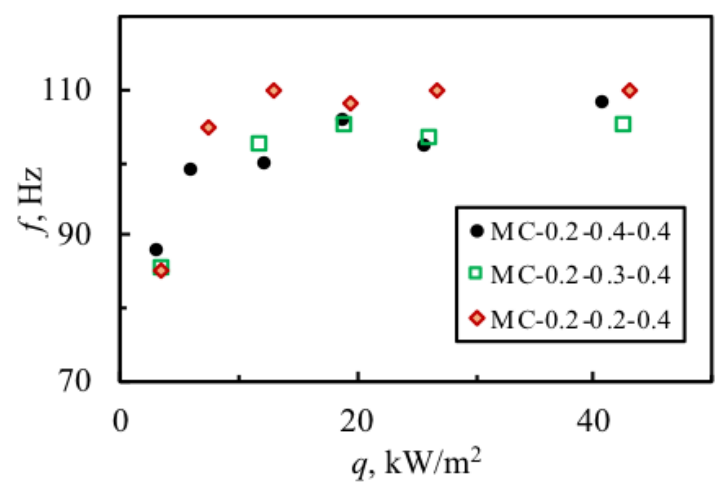

a)

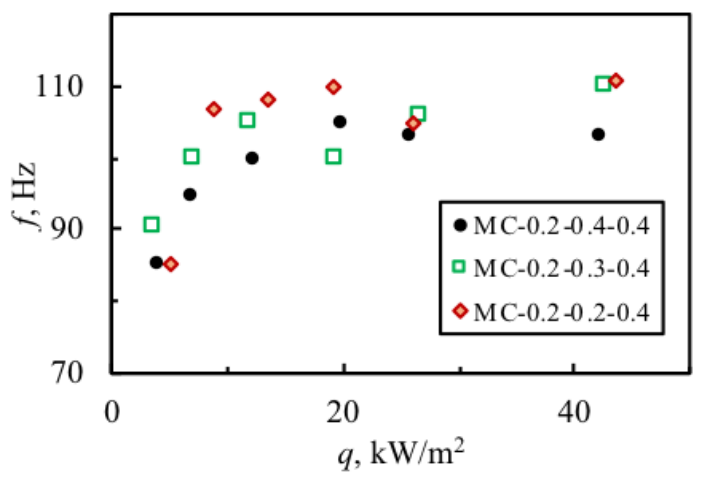

b)

Fig. 9. Averaged departing bubble frequencies for a) Novec649 , b) FC-72. 


\section{Conclusion}

The experimental studies presented in this paper led to the following conclusions:

- The HTC on surfaces with best performance were nearly four times higher for Novec-649 and about three times higher for FC-72 than for plain surfaces.

- For both tested liquids, increasing the channel depth (with a constant microchannel width of $0.2 \mathrm{~mm}$ ) contributed to the increase in heat transfer coefficient.

- For small superheats between the heating surface and the liquid, vapour bubbles had spherical shapes and did not coalesce. At larger superheats, the bubbles interacted strongly, forming large vapour structures.

- Bubble diameters and departure frequencies became stable after reaching the limit of about $10 \mathrm{~kW} / \mathrm{m}^{2}$ both with Novec-649 and FC-72.

\section{Nomenclature}

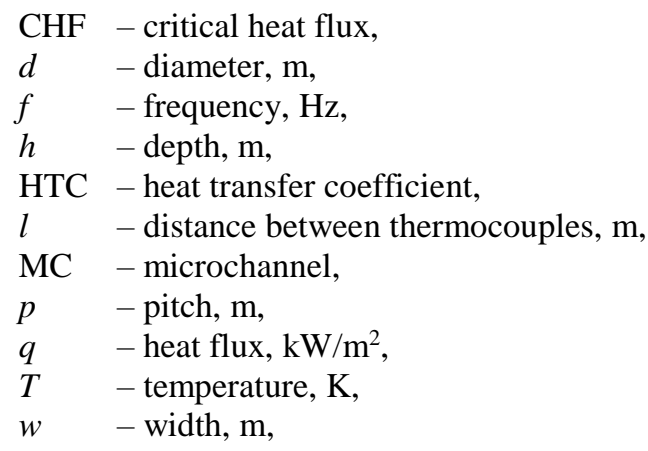

\section{Greek symbols}

$\alpha \quad-$ heat transfer coefficient, $\mathrm{W} /\left(\mathrm{m}^{2} \mathrm{~K}\right)$,

$\delta-$ thickness, mm,

$\lambda-$ thermal conductivity, $\mathrm{W} /(\mathrm{mK})$,

$\Delta T$ - difference of temperature, $\mathrm{K}$,

\section{Subscripts}

$$
\begin{array}{ll}
C u & - \text { copper, } \\
b & - \text { bubble, } \\
S n & - \text { tin, } \\
w & - \text { wall. }
\end{array}
$$

\section{References}

1. R. K. Gouda, M. Pathak, M. Khan, Int. J. Heat \& Mass Transfer 127 (2018)

2. N. Kumar, Md. Raza, R. Raj, Int. J. Therm. Sciences 131 (2018)

3. A. Walunj, A. Sathyabhama, App. Therm. Eng. 128 (2018)

4. Z. Cao, B. Liu, C. Preger, Z. Wua, Y. Zhang, X. Wanga, M. E. Messing, K. Deppert, J. Wei, B. Sundén, Int. J. Heat \& Mass Transfer 126 (2018)

5. A. Jaikumar, S. Kandlikar, App. Therm. Eng. 91 (2015)

6. R. Pastuszko, R. Kaniowski, EPJ Web of Conferences 25, 02019 (2012)

7. R. Pastuszko, EPJ Web of Conferences 45, 01020 (2013)

8. R. Kaniowski, R. Pastuszko, EPJ Web of Conferences 180, 02042 (2018)

9. R. Kaniowski, R. Pastuszko, EPJ Web of Conferences 180, 02041 (2018)

10. R. Pastuszko, Int. J. Therm. Sci. 125 (2018)

11. B. Maciejewska, M. Piasecka, Int. J. Heat Mass Transf. 107 (2017)

12. B. Maciejewska, M. Piasecka, Heat Mass Transf. 53(4) (2017)

13. K. Strąk, M. Piasecka, B. Maciejewska, Int. J. Heat Mass Transf. 117 (2017)

14. B. Maciejewska, K. Strąk, M. Piasecka, Procedia Eng. 157b (2016)

15. M. Piasecka, K. Strąk, B.Grabas, Arch. Metall. Mater. 62(4) (2017) 